\title{
A comprehensive algorithm to distinguish between MPLC and IPM in multiple lung tumors patients
}

\author{
Jun Shao ${ }^{1 \#}$, Chengdi Wang' ${ }^{1 \#}$, Jingwei Li ${ }^{1}$, Lujia Song ${ }^{2}$, Linhui Li ${ }^{1}$, Panwen Tian ${ }^{1}$, Weimin Li $^{1}$ \\ ${ }^{1}$ Department of Respiratory and Critical Care Medicine, West China Medical School/West China Hospital, Sichuan University, Chengdu, China; \\ ${ }^{2}$ West China School of Public Health, Sichuan University, Chengdu, China \\ Contributions: (I) Conception and design: All authors; (II) Administrative support: P Tian, W Li; (III) Provision of study materials or patients: All \\ authors; (IV) Collection and assembly of data: J Shao, C Wang; (V) Data analysis and interpretation: J Li, L Song, L Li; (VI) Manuscript writing: All \\ authors; (VII) Final approval of manuscript: All authors. \\ "These authors contributed equally to this work. \\ Correspondence to: Panwen Tian, PhD; Weimin Li, PhD. Department of Respiratory and Critical Care Medicine, West China Medical School/West \\ China Hospital, Sichuan University, Chengdu, China. Email: mrascend@163.com; weimi003@scu.edu.cn.
}

Background: Diagnosis of multiple lung nodules has become convenient and frequent due to the improvement of computed tomography (CT) scans. However, to distinguish intrapulmonary metastasis (IPM) from multiple primary lung cancer (MPLC) remains challenging. Herein, for the accurate optimization of therapeutic options, we propose a comprehensive algorithm for multiple lung carcinomas based on a multidisciplinary approach, and investigate the prognosis of patients who underwent surgical resection.

Methods: Patients with multiple lung carcinomas who were treated at West China Hospital of Sichuan University from April, 2009 to December, 2017, were retrospectively identified. A comprehensive algorithm combining histologic assessment, molecular analysis, and imaging information was used to classify nodules as IPM or MPLC. The Kaplan-Meier method was used to estimate survival rates, and the relevant factors were evaluated using the log-rank test or Cox proportional hazards model.

Results: The study included 576 patients with 1,295 lung tumors in total. Significant differences were observed between the clinical features of 171 patients with IPM and 405 patients with MPLC. The final classification consistency was 0.65 and 0.72 compared with the criteria of Martini and Melamed (MM) and the American College of Chest Physicians (ACCP), respectively. Patients with independent primary tumors had better overall survival (OS) than patients with intra-pulmonary metastasis (HR =3.99, 95\% CI: 2.86-5.57; $\mathrm{P}<0.001)$. Nodal involvement and radiotherapy were independent prognostic factors.

Conclusions: The comprehensive algorithm was a relevant tool for classifying multifocal lung tumors as MPLC or IPM, and could help doctors with precise decision-making in routine clinical practice. Patients with multiple lesions without lymph node metastasis or without radiotherapy tended to have a better prognosis.

Keywords: Intrapulmonary metastasis (IPM); multiple primary lung cancer (MPLC); comprehensive algorithm; survival

Submitted May 20, 2020. Accepted for publication Aug 18, 2020.

doi: $10.21037 / \mathrm{atm}-20-5505$

View this article at: http://dx.doi.org/10.21037/atm-20-5505

\section{Introduction}

In recent years, the mortality of lung cancer has been significantly reduced through screening with low-dose helical computed tomography (CT) $(1,2)$. However, the identification of multiple lung nodules has emerged as an increasingly common clinical problem (3-5). One previous study suggested that more than $15 \%$ of lung cancer patients had multiple lesions (6). Relative to the general population, patients with lung cancer had a 3.5 -fold increased risk of 
all second cancer (7). To better individualize treatment, it is crucial for clinicians to be able to differentiate between intrapulmonary metastasis (IPM) and multiple primary lung cancer (MPLC). In the latest TNM classification system, lung cancer is classified as: T3 if more than one nodule is found in one lobe, $\mathrm{T} 4$ if a different ipsilateral lobe is involved, and M1a if the contralateral side is affected $(8,9)$. However, this criteria defaulted to patients with multiple nodules as IPM. Neglecting cases of MPLC and confusing two types of multifocal lung cancer patients, this classification might lead to clinical errors. Moreover, patients with independent primary tumors tend to have a better prognosis than those with IPM (10-12). A metaanalysis indicated that the overall survival (OS) of patients with MPLC was superior to that of patients with IPM (HR $=2.66,95 \%$ CI: $1.30-5.44 ; \mathrm{P}=0.007)(12)$.

Unfortunately, despite the issue being widely discussed, no golden standard for distinguishing multiple primary tumors from metastatic lung carcinomas exists. As early as 1975, Martini and Melamed (MM) proposed criteria to distinguish separate primary lesions from metastasis, and this has been broadly accepted (13). Their criteria were empirically derived and considered the major histologic type, interval time for metachronous tumors, and tumor location, and the clinical application of MM criteria still needed further scientific discussions and updates. Then criteria introduced by the American College of Chest Physicians (ACCP) combined the comprehensive histologic assessment of the MM criteria with the evaluation of morphology, immunohistochemistry, and molecular features (14-16). Girard et al. further proposed the comprehensive histologic assessment (CHA) that appeared to be a promising way to determine whether multiple lung carcinomas were metastatic or multiple primaries (17). CHA included a semi-quantitative grading system assessing growth patterns and cytologic features for the first time. After that, the International Association for the Study of Lung Cancer Staging (IASLC) developed clinical and pathological recommendations for identifying solely second primary lung cancers (10). Nevertheless, there was no accurate method to identify which lesions have arisen from one another. The actual process of metastasis was too complex to found biomarkers, which was influenced not only by the intrinsic and epigenetic determinants of tumor cells, but also by a series of complex tumor host interactions between the primary and the metastatic sites $(18,19)$.

Recently, a growing number of studies have validated genomic testing can be used to confirm the consistency of the tumor lineage (20-23). Genomic profiling of single genes or a subset of genes and DNA rearrangement profiles had been shown to be efficient $(22,24-26)$. Then the implementation of next-generation sequencing (NGS) further enhance the accuracy of molecular testing (27-29). However, these detection technologies carry the disadvantages of having limited sensitivity and high costs of clinical implementation. Another potential technique is radiology, because CT has become more widely used. Suh et al. suggested IPM should be considered if both of two suspected malignant lesions appear as solid predominant lesions without spiculation or air-bronchogram on CT (30). Moreover, none of method has clear guidelines for rare histological subtyping of lung cancer or more than two nodules, which may result in defects in clinical practice. Here, we report a comprehensive proposal for distinguishing IPM from MPLC in lung cancer, and retrospectively investigate the prognosis after surgical treatment in 576 patients with multiple lung tumors. We present the following article in accordance with the MDAR reporting checklist (available at http://dx.doi.org/10.21037/ atm-20-5505).

\section{Methods}

\section{Patients and tumor selection}

All patients who had undergone resection of lung carcinoma at West China Hospital of Sichuan University in Chengdu, China, between April, 2009, and December, 2017, were retrospectively reviewed. A total of 576 individuals with pathologically confirmed multiple lung carcinomas who had sufficient data available including clinical, histological, molecular characteristics and imaging analysis were enrolled. The following information was also collected for each patient: age (at the time of surgery), sex, smoking history, number of lesions, tumor location, tumor histology, adjuvant therapy, node invasion, pleural invasion, and epidermal growth factor receptor (EGFR) and programmed death-ligand 1 (PD-L1) mutation status. Patients with an interval of less than 6 months between tumors were defined as synchronous, while the remainders were defined as metachronous. All of the patients were followed up until July 8, 2019 to obtain OS. The study was conducted in accordance with the Declaration of Helsinki (as revised in 2013), and the ethics committee of West China Hospital has approved this study (Project No. 2019-195). Because of the retrospective nature of the research, the requirement for informed consent was waived. 


\section{Histologic assessment}

The researchers extracted the histologic information from the patients' pathological records. All tumor slides had been reviewed by experienced pathologists. The 2015 WHO classification reclassified lung cancer into adenocarcinoma, squamous cell carcinoma, small cell carcinoma, large cell carcinoma and other malignant types (31). According to CHA, the predominant histologic pattern was defined according to the histologic component with the greatest percentage (17). In our study, adenocarcinoma subtypes were atypical adenocarcinoma hyperplasia (AAH), adenocarcinoma in situ (AIS), minimally invasive adenocarcinoma (MIA), and invasive adenocarcinoma (IA). IA was further subdivided into lepidic, acinar, papillary, micropapillary, and solid adenocarcinoma. The overall method of detailed histological evaluation also covered cytological and stromal characteristics, including the cell morphology, degree of keratosis, stroma, and necrosis of squamous cell carcinoma. Meanwhile, the status of mediastinal lymph nodes dissected, including N2 and N3 nodes, was also recorded.

\section{Molecular analysis}

Mutational and genomic profiling techniques were performed to assess the clonal relationships between multiple tumors from individual patients, covering 9 genes [EGFR, ALK receptor tyrosine kinase gene (ALK), erb-b2 receptor tyrosine kinase 2 gene (ERBB2), v-raf murine sarcoma viral oncogene homologue B1 (BRAF), MNNG HOS transforming gene (MET), c-ros oncogene 1 receptor tyrosine kinase (ROS1), rearranged during transfection proto-oncogene (RET), kirsten rat sarcoma viral oncogene homolog (KRAS), and tumor protein $\mathrm{p} 53$ gene (TP53)]. More than 50 hotspot mutations were diagnosed in tumor pairs.

\section{Imaging analysis}

The preoperative CT images were reviewed and nodule information was extracted from the imaging reports. Lesions were classified into four types: pure ground-glass nodule (GGN), ground-glass opacity (GGO)-predominant part-solid nodule (PSN), solid-predominant PSN, and pure solid nodule (32). In addition, the malignant features of the nodules were evaluated for spiculation and lobulation. Simultaneously, systemic metastasis was confirmed by
PACS (picture archiving and communication system) reports. Extrapulmonary metastases, such as brain or bone metastases, were considered to be distant metastases.

\section{Algorithm for multiple lung tumors}

The algorithm, which was based on multidisciplinary criteria (Figure 1), classified multiple nodules as IPM or MPLC. First, metachronous nodules were defined as MPLCs if the time period between nodules was above the threshold of 5 years. Second, each nodule was fully evaluated by histology. Tumors of different histological types or with tumors in situ were considered to be MPLC. If all tumors were unusual histologic types, such as neuroendocrine carcinoma, the patient was classified as IPM. Adenocarcinomas with different or rare predominant architectural patterns were also defined as metastasis in the lung. Lymph node metastases and distant metastases also indicated IPM. Thirdly, the molecular results determined whether tumors pairs were IPM or MPLC. Tumors which shared at least two gene mutations or one rare mutation in common were classified as IPM. Finally, the lesion features on preoperative imaging was used to obtain the final classification. When a nodule was pure GGN/GGOdominant or harbored spiculation/lobulation, it was defined as MPLC. Furthermore, patients who had three or more lung cancer nodules with any two nodules presenting a metastatic relationship were considered to be IPM.

\section{Previous criteria}

According to the MM criteria, IPM was classified when: tumor pairs, with synchronous tumors of a similar histological subtype which were located in same segment and/or without adenocarcinoma in situ, or with presence of carcinoma in the shared lymphatics of the two paired tumors (Table S1) (13). Metachronous tumors were defined as MPLCs when the tumor interval was $>2$ years. In cases where the time interval between tumors was $<2$ years, if the two tumors were located in the same lobe, or nodal involvement or systemic metastasis, these tumor pairs would be defined as IPMs.

According to the ACCP criteria, tumors with the same histological subtypes were seen as MPLCs if they were located in different lobes with no nodal involvement or systemic metastases, and the time period between tumors in a pair were less than 4 years; as IPM with the presence of lymphatic or systemic metastases and/or a short interval of 


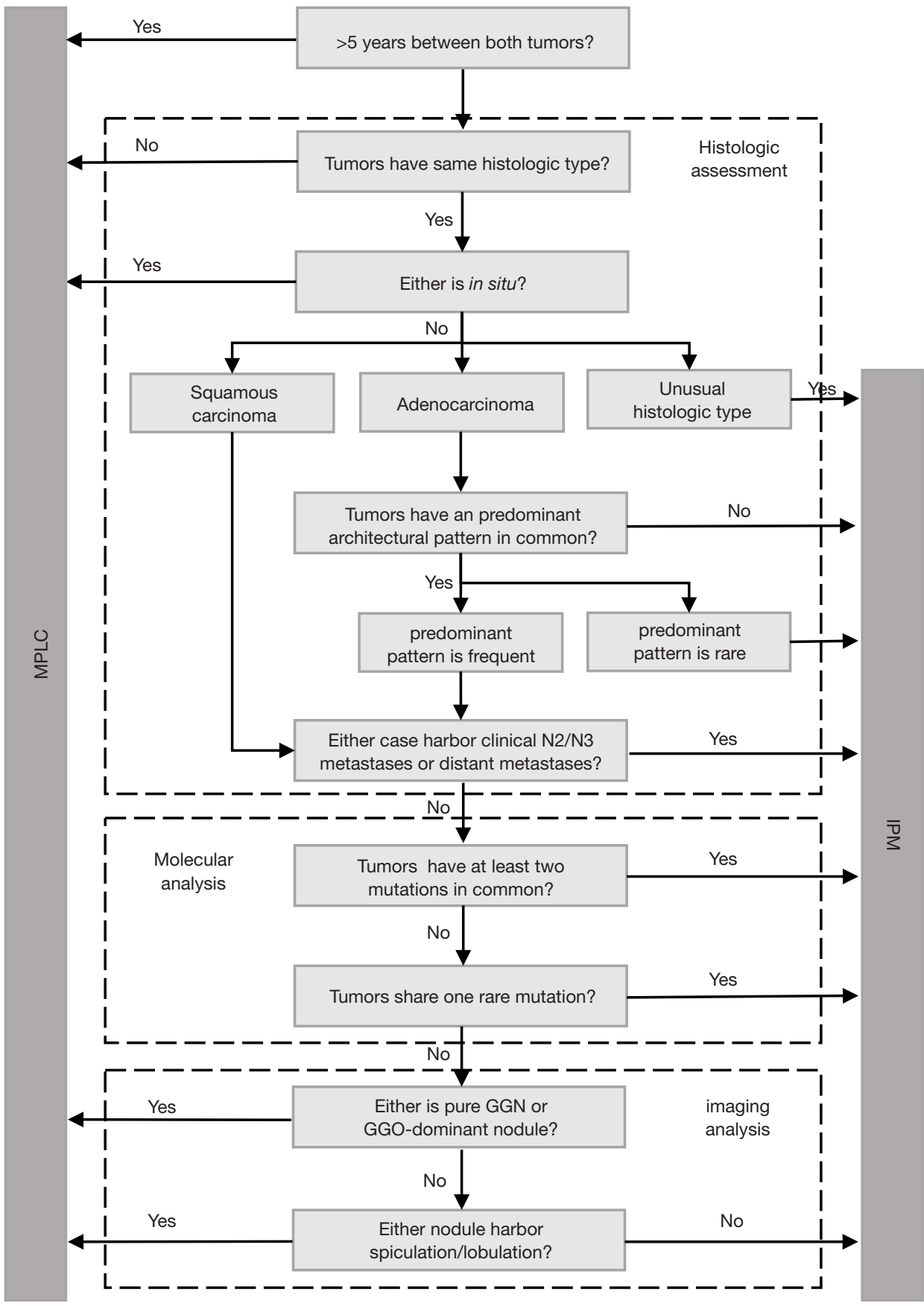

Figure 1 The comprehensive algorithm for patients with multiple lung tumors. Tumor in situ are defined as atypical carcinoma hyperplasia, and lung cancer in situ. Unusual histologic types are defined as other types of lung cancer apart from adenocarcinoma and squamous cell carcinoma. The rare predominant pattern of adenocarcinoma is defined as midpapillary. The rare mutation is defined as TP53. MPLC, multiple primary lung cancer; IPM, intrapulmonary metastasis; GGN, pure ground-glass nodule; GGO, ground-glass opacity. 
less than 2 years. In addition, tumors of different histological subtypes, tumors with the same histological subtype but exhibiting different molecular genetic characteristics and carcinomas in situ were defined as MPLAs as well (Table S1) (14-16).

\section{Statistical analyses}

The clinical, histological, and molecular characteristics, and imaging features of the patients were collected from the Hospital Information System. To compare the clinical characteristics of patients with IPM and MPLC, continuous and categorical variables were analyzed by Student's $t$-test and chi-square test, respectively. The consistency of different classification methods was assessed using Cohen $\kappa$ score (33). OS was measured from the first surgical resection to death or the last follow-up. The OS rate was estimated using the Kaplan-Meier method. The log-rank test and Cox hazards regression analysis were performed to identify the effect of factors on survival in univariate analysis. The Cox model was used in multivariate analysis for variables that were significantly associated with OS. Analyses were performed with IBM SPSS Statistics for Windows, Version 23.0. Armonk, NY: IBM Corp. A P value of $<0.05$ was considered to be statistically significant.

\section{Results}

\section{Patients and histological characteristics}

The 576 patients with multiple lung cancers included in this study were predominantly male (301 of $576,52 \%)$ and non-smokers (340 of 576, 59\%) (Table 1). Of the patients, 330 had synchronous tumors, while 246 patients had metachronous tumors with multiple tumors more than 6 months after resection. Over half of the patients were found to have malignant tumors located in different ipsilateral lobes (325 of 576, 56\%), followed by contralateral lesions (196 of 576, 34\%).

Of 1,295 tumors, the predominant carcinoma type was adenocarcinoma (1,041 of $1,295,80 \%)$, among which, acinar (228 of 1,041, 22\%), lepidic, and papillary adenocarcinoma were the three most frequent architectural patterns. In all cases of lung nodules, $44 \%$ of all patients had undergone lobectomy (575 of 1,295, 44\%), and wedge resection was also common (336 of 1,295, 26\%). Overall, the tumors were more likely to occur on the right side (791 of $1,295,61 \%$ ), and most were $\leq 3 \mathrm{~cm}$ in size when detected or resected (927 of $1,295,72 \%)$.

\section{Patients with IPM or MPLC}

The comprehensive criteria identified 171 patients with IPM and 405 cases of MPLC. Compared with the MM classification, we found discordance for 84 patients $(\kappa=0.65)$ (Figure 2). Among the patients, 42 had MPLC according to the MM criteria but were classified as IPM according to our final classification based on a time to relapse of $>2$ years $(\mathrm{n}=37)$ and the presence of more than two nodules $(n=5)$. Meanwhile, 42 patients had IPM according to MM criteria but were reclassified as MPLC according to our final classification based on nodules being located in the same lobe or segment $(n=36)$ and different predominant patterns of adenocarcinoma $(n=6)$. At the same time, the $\kappa$ consistency between our method and the ACCP criteria was 0.72 with 73 different patients (Figure 2). Of the patients, 15 had MPLC according to the ACCP criteria but were reclassified as IPM according to the final classification based on them having a rare histological type $(n=3)$, more than two nodules $(n=3)$, and a time to relapse of $>2$ years $(\mathrm{n}=9)$. Meanwhile, 58 patients had IPM according to ACCP criteria but were reclassified as MPLC according to the final classification based on nodules being located in the same lobe or segment $(n=47)$ and a time to relapse of $<2$ years $(\mathrm{n}=11)$.

In our final classification, more than half of the men (106 of 171) were placed in the IPM group, with less than half of the men (195 of 405) being placed in the MPLC group (Table 2). The median age at first resection of the IPM group was 57.69 years old, and that of the MPLC group was 59.56 years old. The proportion of smokers in the two groups was $48 \%$ (82 of 171) and 64\% (258 of 405), respectively. There were significant differences between patients with IPM and MPLC in terms of gender $(\mathrm{P}<0.001)$, age at first resection $(\mathrm{P}=0.028)$, and smoking history $(\mathrm{P}<0.001)$. There were also statistically significant differences between the groups in relation to tumor chronology $(\mathrm{P}=0.010)$, tumor side $(\mathrm{P}=0.016)$, nodal involvement $(\mathrm{P}<0.001)$, pleural invasion $(\mathrm{P}=0.001)$, chemotherapy $(\mathrm{P}<0.001)$, radiotherapy $(\mathrm{P}<0.001)$, and $\mathrm{PD}-\mathrm{L} 1$ mutational status $(\mathrm{P}=0.001)$.

\section{Follow-up and survival}

In the univariate analysis, OS for all 576 patients who harbored multiple lung tumors was associated with gender $(\mathrm{P}<0.001)$, smoking history $(\mathrm{P}<0.001)$, nodal involvement 
Table 1 The clinical and histological characteristics of 576 patients with multiple lung tumors

\begin{tabular}{|c|c|c|}
\hline Variables & Value & Proportion \\
\hline Patient characteristics & 576 & \\
\hline \multicolumn{3}{|l|}{ Gender } \\
\hline Male & 301 & $52 \%$ \\
\hline Female & 275 & $48 \%$ \\
\hline $\begin{array}{l}\text { Mean age at first resection, years } \\
(\text { mean } \pm S D)\end{array}$ & $59.01 \pm 9.32$ & \\
\hline \multicolumn{3}{|l|}{ Smoking history } \\
\hline Never & 340 & $59 \%$ \\
\hline Current or former & 235 & $41 \%$ \\
\hline Unknown & 1 & $<1 \%$ \\
\hline \multicolumn{3}{|c|}{ Patients with different tumor chronology } \\
\hline Synchronous & 330 & $57 \%$ \\
\hline Metachronous & 246 & $43 \%$ \\
\hline \multicolumn{3}{|l|}{ Distribution of tumors } \\
\hline Ipsilateral (same lobe) & 55 & $10 \%$ \\
\hline Ipsilateral (other lobe) & 325 & $56 \%$ \\
\hline Contralateral & 196 & $34 \%$ \\
\hline Tumor characteristics & 1,295 & \\
\hline \multicolumn{3}{|l|}{ Carcinoma type } \\
\hline Adenocarcinoma & 1,041 & $80 \%$ \\
\hline Squamous carcinoma & 209 & $16 \%$ \\
\hline Adenosquamous carcinoma & 17 & $1 \%$ \\
\hline Small cell carcinoma & 16 & $1 \%$ \\
\hline Others & 12 & $<1 \%$ \\
\hline $\begin{array}{l}\text { Predominant pattern of } \\
\text { adenocarcinoma }\end{array}$ & 1,041 & \\
\hline AAH & 36 & $3 \%$ \\
\hline AIS & 64 & $6 \%$ \\
\hline MIA & 93 & $9 \%$ \\
\hline Lepidic & 194 & $19 \%$ \\
\hline Acinar & 228 & $22 \%$ \\
\hline Papillary & 98 & $9 \%$ \\
\hline Micropapillary & 10 & $1 \%$ \\
\hline Solid & 43 & $4 \%$ \\
\hline Other & 275 & $26 \%$ \\
\hline
\end{tabular}

Table 1 (continued)
Table 1 (continued)

\begin{tabular}{|c|c|c|}
\hline Variables & Value & Proportion \\
\hline \multicolumn{3}{|l|}{ Type of resection } \\
\hline Lobectomy & 575 & $44 \%$ \\
\hline Segmentectomy & 256 & $20 \%$ \\
\hline Wedge resection & 336 & $26 \%$ \\
\hline Nonanatomic resection & 121 & $9 \%$ \\
\hline Other & 7 & $<1 \%$ \\
\hline \multicolumn{3}{|l|}{ Side } \\
\hline Right & 791 & $61 \%$ \\
\hline Left & 496 & $38 \%$ \\
\hline Other & 8 & $1 \%$ \\
\hline \multicolumn{3}{|l|}{ Tumor size, $\mathrm{cm}$} \\
\hline$\leq 3$ & 927 & $72 \%$ \\
\hline $3-5$ & 188 & $15 \%$ \\
\hline $5-7$ & 48 & $4 \%$ \\
\hline$>7$ & 28 & $2 \%$ \\
\hline Unknown & 88 & $7 \%$ \\
\hline
\end{tabular}

\begin{tabular}{|l|c|c|c|l|}
\hline \multirow{2}{*}{$\begin{array}{l}\text { MM } \\
\text { classification }\end{array}$} & \multicolumn{3}{|c|}{ Final classification } & \multirow{3}{*}{} \\
\cline { 2 - 4 } & MPLC & IPM & Total & \multirow{2}{*}{ $=0.65$} \\
\hline MPLC & 363 & 42 & 405 & \multirow{2}{*}{$\mathrm{P}<0.001$} \\
\hline IPM & 42 & 129 & 171 & \\
\hline Total & 405 & 171 & 576 & \\
\hline
\end{tabular}

\begin{tabular}{|c|c|c|c|c|}
\hline \multirow{2}{*}{$\begin{array}{l}\text { ACCP } \\
\text { classification }\end{array}$} & \multicolumn{3}{|c|}{ Final classification } & \multirow{5}{*}{$\begin{array}{l}\kappa=0.72 \\
P<0.001\end{array}$} \\
\hline & MPLC & IPM & Total & \\
\hline MPLC & 347 & 15 & 362 & \\
\hline IPM & 58 & 156 & 214 & \\
\hline Total & 405 & 171 & 576 & \\
\hline
\end{tabular}

Figure 2 A comparison of the final classification with $M M$ and ACCP classification. MM, Martini and Melamed; ACCP, American College of Chest Physicians; MPLC, multiple primary lung cancer; IPM, intrapulmonary metastasis. 
Table 2 The clinical, histological, and molecular characteristics of the IPM and MPLC patients

\begin{tabular}{|c|c|c|c|}
\hline Variables & $\begin{array}{c}\text { IPM } \\
(n=171)\end{array}$ & $\begin{array}{l}\text { MPLC } \\
(n=405)\end{array}$ & $P$ value \\
\hline Gender & & & $<0.001$ \\
\hline Male & 106 & 195 & \\
\hline Female & 65 & 210 & \\
\hline $\begin{array}{l}\text { Mean age at first resection, } \\
\text { years (mean } \pm S D \text { ) }\end{array}$ & $57.69 \pm 9.27$ & $59.56 \pm 9.31$ & 0.028 \\
\hline Smoking history & & & $<0.001$ \\
\hline Never & 82 & 258 & \\
\hline Current or former & 89 & 146 & \\
\hline Unknown & 0 & 1 & \\
\hline Number of lesions & & & 0.657 \\
\hline 2 & 142 & 330 & \\
\hline$\geq 3$ & 29 & 73 & \\
\hline Tumor chronology & & & 0.010 \\
\hline Synchronous & 84 & 246 & \\
\hline Metachronous & 87 & 159 & \\
\hline Side & & & 0.016 \\
\hline Ipsilateral (same lobe) & 14 & 41 & \\
\hline Ipsilateral (other lobe) & 112 & 213 & \\
\hline Contralateral & 45 & 151 & \\
\hline Nodal involvement & & & $<0.001$ \\
\hline NO or Nx (both tumors) & 24 & 369 & \\
\hline $\mathrm{N}$-positive ( $\geq 1$ tumor) & 145 & 27 & \\
\hline Unknown & 2 & 9 & \\
\hline Pleural invasion & & & 0.001 \\
\hline No (both tumor) & 69 & 235 & \\
\hline Yes ( $\geq 1$ tumor) & 96 & 161 & \\
\hline Unknown & 6 & 9 & \\
\hline Chemotherapy & & & $<0.001$ \\
\hline Yes & 115 & 126 & \\
\hline No & 56 & 279 & \\
\hline Radiotherapy & & & $<0.001$ \\
\hline Yes & 32 & 25 & \\
\hline No & 139 & 380 & \\
\hline
\end{tabular}

Table 2 (continued)
Table 2 (continued)

\begin{tabular}{lccc}
\hline Variables & $\begin{array}{c}\text { IPM } \\
(\mathrm{n}=171)\end{array}$ & $\begin{array}{c}\text { MPLC } \\
(\mathrm{n}=405)\end{array}$ & P value \\
\hline $\begin{array}{l}\text { EGFR status } \\
\text { Wild-type }\end{array}$ & 58 & 109 & 0.152 \\
Mutated & 44 & 131 & \\
Unknown & 69 & 165 & \\
PD-L1 & & & 0.001 \\
Positive & 65 & 76 & \\
Negative & 21 & 87 & \\
Unknown & 85 & 242 &
\end{tabular}

IPM, intrapulmonary metastasis; MPLC, multiple primary lung cancer; EGFR, epidermal growth factor receptor; PD-L1, programmed death-ligand 1.

$(\mathrm{P}<0.001)$, pleural invasion $(\mathrm{P}=0.002)$, chemotherapy $(\mathrm{P}=0.006)$, radiotherapy $(\mathrm{P}<0.001)$, and the mutational status of EGFR $(\mathrm{P}<0.001)$ and $\mathrm{PD}-\mathrm{L} 1(\mathrm{P}<0.001)($ Table 3$)$. In the multivariate analysis, nodal involvement $(\mathrm{P}=0.04)$ and radiotherapy $(\mathrm{P}=0.04)$ were independent prognostic factors of OS.

Notably, no matter which method was used to classify multifocal lung cancer, patients with independent primary tumors had a significantly better prognosis than patients with IPM (Table 3, Figure 3) (MM classification: HR =3.28, 95\% CI: 2.35-4.58; $\mathrm{P}<0.001$; ACCP classification: HR $=4.02,95 \%$ CI: 2.85-5.67; $\mathrm{P}<0.001$; final classification: $\mathrm{HR}=3.99,95 \% \mathrm{CI}: 2.86-5.57 ; \mathrm{P}<0.001)$. In patients with MPLC, the multivariate analysis showed that never smoking $(\mathrm{P}=0.004)$ was associated with survival (Table S2). In patients with IPM, most of the variables had no correlation with survival except tumor number (Table S3).

\section{Discussion}

With the diffusion of high-resolution CT screening, the detection rate of lung nodules has improved. However, the correct diagnosis of patients with multinodular lung cancer has become a concern $(34,35)$. In this study, we have presented a comprehensive algorithm for multiple lung carcinomas which combines histologic, molecular, and imaging information. The algorithm divided the types of lung cancer in detail and made recommendations 
Table 3 Univariate and multivariate analyses of overall survival

\begin{tabular}{|c|c|c|c|c|c|}
\hline Variable & \multicolumn{3}{|c|}{ Univariate analysis } & \multicolumn{2}{|c|}{ Multivariate analyses } \\
\hline Gender & & $<0.001$ & $0.49(0.34-0.7)$ & 0.28 & \\
\hline Male & $32 \%(19-45 \%)$ & & & & \\
\hline Female & $64 \%(52-77 \%)$ & & & & \\
\hline$\leq 60$ years & $48 \%(34-61 \%)$ & & & & \\
\hline$>60$ years & $37 \%(19-55 \%)$ & & & & \\
\hline Smoking history & & $<0.001$ & $2.38(1.7-3.35)$ & 0.19 & \\
\hline No & $58 \%(46-71 \%)$ & & & & \\
\hline 2 & $34 \%(20-47 \%)$ & & & & \\
\hline$\geq 3$ & $78 \%(66-90 \%)$ & & & & \\
\hline Tumor chronology & & 0.53 & $0.9(0.64-1.26)$ & & \\
\hline Synchronous & $53 \%(39-66 \%)$ & & & & \\
\hline Metachronous & $43 \%(31-55 \%)$ & & & & \\
\hline Location & & 0.28 & $0.73(0.41-1.29)$ & & \\
\hline Same lobe & $37 \%(-15-89 \%)$ & & & & \\
\hline Different lobes & $43 \%(32-55 \%)$ & & & & \\
\hline Yes ( $\geq 1$ tumor) & $40 \%(28-51 \%)$ & & & & \\
\hline Chemotherapy & & 0.006 & $1.6(1.14-2.24)$ & 0.86 & \\
\hline No & $64 \%(54-75 \%)$ & & & & \\
\hline Yes & $31 \%(18-45 \%)$ & & & & \\
\hline Radiotherapy & & $<0.001$ & $2.25(1.52-3.33)$ & 0.04 & $2.4(1.05-5.49)$ \\
\hline No & $50 \%(36-63 \%)$ & & & & \\
\hline Yes & $19 \%(5-33 \%)$ & & & & \\
\hline EGFR status & & $<0.001$ & $0.45(0.28-0.7)$ & 0.22 & \\
\hline Wild-type & $19 \%(-8-46 \%)$ & & & & \\
\hline Mutated & $57 \%(39-75 \%)$ & & & & \\
\hline
\end{tabular}

Table 3 (continued) 
Table 3 (continued)

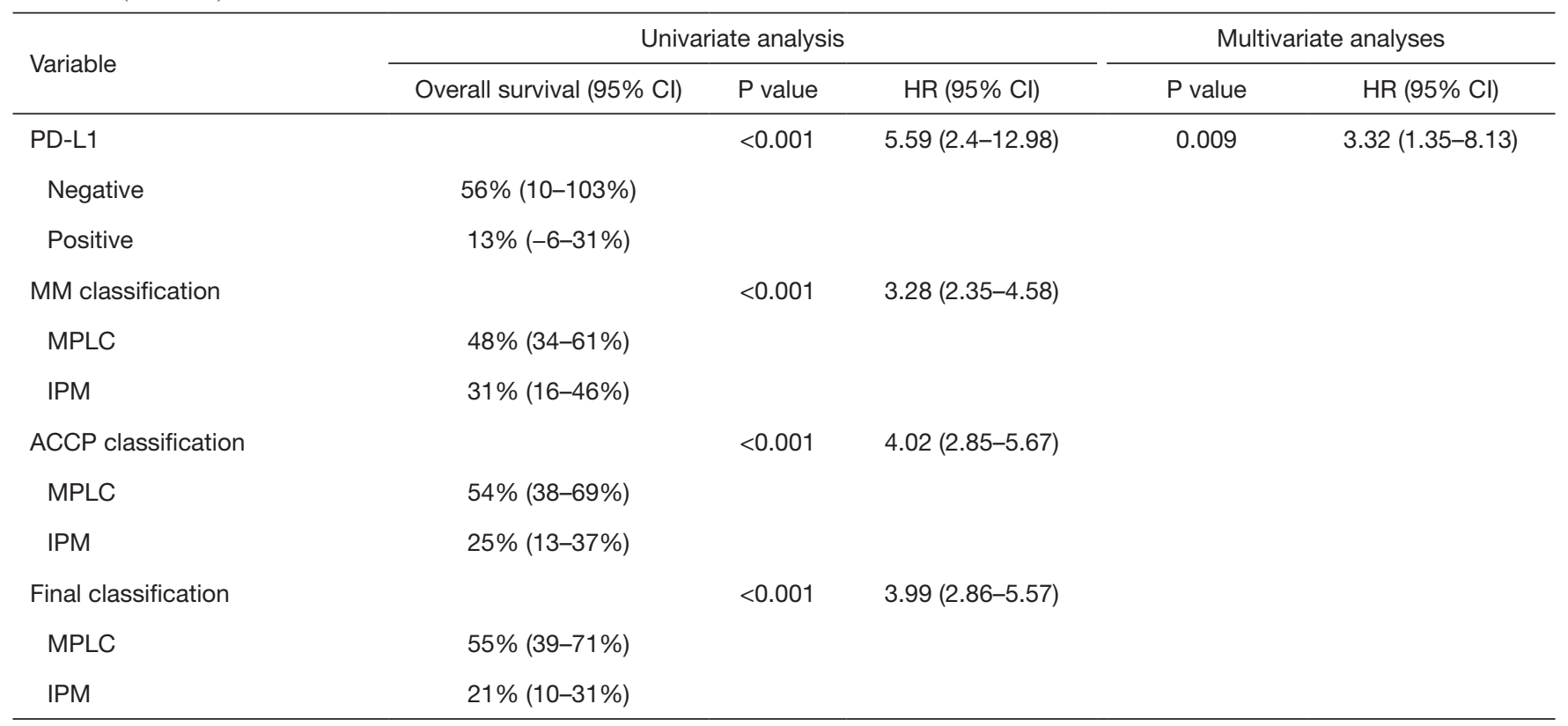

EGFR, epidermal growth factor receptor; PD-L1, programmed death-ligand 1; MPLC, multiple primary lung cancer; IPM, intrapulmonary metastasis; ACCP, American College of Chest Physicians.

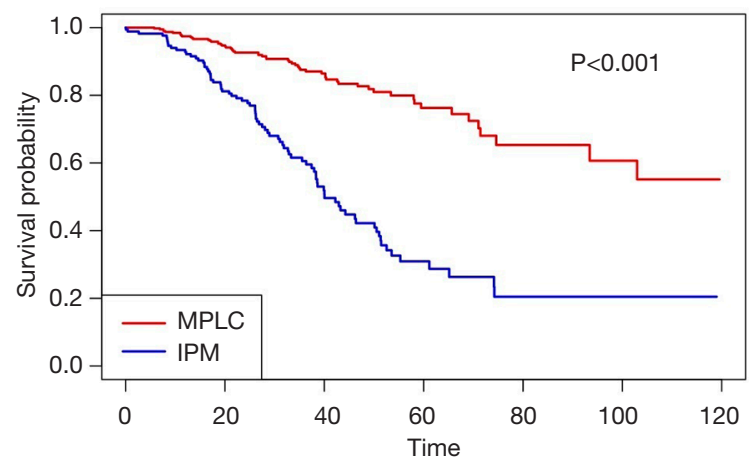

Figure 3 The survival curves of the IPM and MPLC patients after the final classification. MPLC, multiple primary lung cancer; IPM, intrapulmonary metastasis.

for more than two tumors. To explore the predictors of survival outcomes in patients with multiple lung tumors after surgical treatment, we performed an analysis of clinical characteristics and OS to compare IPM and MPLC. Notably, our results showed that the clinical characteristics of patients with IPM were clearly different from those with MPLC. Also, the OS of the IPM group was significantly higher than that of the MPLC group. Survival analysis underlined the survival benefit of being node-negative and not receiving radiotherapy in patients with multiple lung cancers.

Although the TNM staging system is based on the best available current evidence, there is conflict between cTNM (clinical TNM) and pTNM (pathological TNM) in patients with multiple lesions. According to the eighth TNM classification system, whenever two or more lung nodules are present, they are classified as T3, T4, or M1 depending on the location of the tumors (36). These multinodular patients, who are upgraded to stage III or stage IV, are usually treated with chemotherapy or radiation, and have a poor prognosis. However, our study confirmed that the IPM and MPLC groups not only had completely different clinical characteristics, but also held significantly different survival rates. Patients with intra-pulmonary metastasis had significantly worse OS than patients with primary lung tumors $(\mathrm{HR}=3.99,95 \% \mathrm{CI}: 2.86-5.57 ; \mathrm{P}<0.001)$. The 5 -year survival rate in the patients with MPLC was $81.8 \%$, whereas the survival rate in patients with IPM was $40.2 \%$ (11). IPM represents the advanced stage of lung cancer. This is the biggest difference between IPM and MPLC, and the reason why doctors need to distinguish between the two for precise treatment. These results are consistent with those of previous studies (Table S4) $(5,11,26,37,38)$.

Recently, IASLC proposed the Criteria to Distinguish 
Synchronous Second Primary Lung and Related Pulmonary Tumor, taking imaging, biopsy, and clinical features into account (10). However, the process of tumor metastasis has remained ambiguous $(39,40)$. Table 4 summarized several main criteria and latest methods for multiple lung cancer. Here, we presented a clinical classification method for defining multiple lung carcinomas, which is an improvement on the existing methods and technology. Compared with previous criteria, our comprehensive algorithm combined multidisciplinary criteria including histologic assessment, molecular analysis and imaging analysis. The distinguishing process was verified in the large population, based on the latest evidence of evidence-based medicine. In addition, we considered the rare subtypes of lung cancer and patients with more than two pulmonary nodules for the first time. In general, our algorithm was more scientific and more suitable for clinical work.

Previous studies have confirmed that metachronous cancers may be IPM even if relapse occurs after 2 years, but no IPM occurs later than five years (10). For this reason, a threshold of five years was chosen in our research for defining metachronous nodules as MPLC, rather than the two-year threshold used by the previous criteria. Histological assessment has always been an important part of defining multiple lesions. The subtypes of cancers that do not occur very often are considered 'rare'; these included adenosquamous carcinoma and carcinoids (41). Meanwhile, lung cancers other than adenocarcinoma and squamous cell carcinoma with a low incidence were defined as "unusual". For adenocarcinoma, morphological assessment of architectural patterns was mostly effective when the predominant patterns were rare midpapillary. Molecular analysis has emerged as a rising technology in recent years. With the help of powerful biological analysis tools, we have developed an understanding of the mechanism of various genes involved in tumorigenesis. We chose these 9 genes that were associated with evolution of lung cancer $(25,42,43)$. Herein the common drivers of tumor were considered as markers of the similar origin, and vice versa. For example, the mutational status of the TP53 gene was discordant in multiple lung cancer patients, suggesting a different clonal origin despite the fact that most of them had almost identical histologic features (44). What's more important, eight genes except TP53 were recommended by National Comprehensive Cancer Network (NCCN), which played an important role in the subsequent selection of targeted drugs (45). Furthermore, imaging is able to reveal the characteristics of preoperative nodules. It has been confirmed that the higher the number of nodular groundglass components, the higher the number of malignant features, and the more likely the nodules are to be primary nodules (30).

In this study, we included a large number of multiple lung cancer patients who had undergone resections. Nonsmokers accounted for the majority of patients. Previous research has suggested that lung cancer in individuals have

Table 4 Main criteria and latest methods for multiple lung cancer

\begin{tabular}{|c|c|c|}
\hline Proposer, year & Criteria/methods & Characteristics \\
\hline $\begin{array}{l}\text { Detterbeck FC, } \\
\text { 2003; } \\
\text { Shen KR, 2007; } \\
\text { Kozower BD, } 2013 \\
\text { (ACCP criteria) } \\
(14-16)\end{array}$ & $\begin{array}{l}\text { IPM: tumors with the presence of lymphatic or systemic metastases and/or } \\
\text { a short interval of less than } 2 \text { years; } \\
\text { MPLC: tumors with the same histological subtypes if they were located } \\
\text { in different lobes with no nodal involvement or systemic metastases, and } \\
\text { the time period between tumors in a pair were less than } 4 \text { years; tumors of } \\
\text { different histological subtypes, tumors with same histological subtype but } \\
\text { exhibiting different molecular genetic characteristics and carcinomas in situ }\end{array}$ & $\begin{array}{l}\text { - This criteria were based on the } \\
\text { evaluation of morphology, } \\
\text { immunohistochemistry, and molecular } \\
\text { features }\end{array}$ \\
\hline
\end{tabular}

Table 4 (continued) 
Table 4 (continued)

\begin{tabular}{ll}
\hline Proposer, year & Criteria/methods \\
\hline Nicolas Girard, & The overall method of comprehensive histologic assessment included \\
2009 & evaluation of percentages of histologic subtypes, histologic features, \\
$(\mathrm{CHA})(17)$ & stromal characteristics, lymphoid hyperplasia and/or necrosis. For \\
& squamous cell carcinoma, detailed histologic assessment included the \\
& cytologic morphology, amount of keratinization, appearance of the stroma, \\
& necrosis, as well the presence of histologic components. Paired tumors \\
& exhibiting similar histological features were considered as IPM, and those \\
& showing different histologic features as MPLC
\end{tabular}

Frank C. IPM: matching appearance on comprehensive histologic assessment; the Detterbeck, 2016 same biomarker pattern; significant nodal or systemic metastases; (IASLC criteria) (10) MPLC: they are clearly of a different histologic type; they are clearly different by a comprehensive histologic assessment; they are squamous carcinomas that have arisen from carcinoma in situ; tumors may be considered to be arising from a single tumor source if exactly matching breakpoints are markers; absence of nodal or systemic metastases

Jason C. Chang, This method analyzed by 341-468 gene MSK-IMPACT NGS assay. Tumor 2019 (29) pairs exhibiting entirely non-overlapping, unique mutations were classified as clonally unrelated (MPLC). By contrast, tumors sharing multiple (>2) mutations were regarded as clonally related (IPM)

Stephen J.

Mate-pair sequencing was performed on DNA extracted from multiple lung Murphy, 2019 (23) cancers. Discordant mapping junctions and chromosomal copy levels were assessed for each tumor. Calls of "related" or "independent" lineage were determined based on the numbers of shared and unique somatic junctions per tumor

Audrey Mansuet-Lupo, 2019 (26)

Young Joo Suh, $2020(30)$ First, tumors were classified as MPLC, when one nodule presented as either an in situ adenocarcinoma or a minimally invasive adenocarcinoma. They chose a threshold of 5 years to consider metachronous nodules as MPLAs. Second, tumor pairs were classified as MPLAs or as IPM according to molecular results, except for tumor pairs that harbored the same frequent mutation in the genes KRAS (p.G12X) or EGFR (del19 or p.L858R), which were classified according to the histological classification

A novel algorithm was established with four sequential decision steps. At step 1, the presence of at least one lesion showing a lesion type of pure identified by comparative genomic hybridization; different pattern of bio-

\section{Characteristics}

- This method turned the histologic heterogeneity of lung carcinoma into a powerful tool to accurately classify multiple lung cancers

- All available information be considered in this criteria, including imaging, biopsy, and clinical features;

- Several features were suggestive but associated with potential misclassification including biomarkers and nodal involvement

- Clonality assessment by large panel NGS represents a significant advance over less comprehensive gene panels; - The main limitations of large panel NGS platforms include availability, cost, and turnaround time

- Calling lineage through shared junctions improved the sensitivity of the test;

- Turnaround times and costs remain common challenges for the NGS-based testing

- It is based on histological diagnosis GGN or GGO-predominant PSN within the pair could suggest MPLC. For step 2, a combination of qualitative imaging findings including spiculation and air-bronchogram was used. For step 3, if the two lesions within each pair had more than or equal to two grades of differences of SUV $V_{\max }$, the pair was considered as MPLC. For step 4, if the patient had N2/3 lymph node metastasis or distant metastasis was considered IPM according to the WHO 2015 classification and molecular profiling using next-generation sequencing targeting 22 hotspot genes

- It is based on imaging characters (lesion types, lesion morphology, and difference of SUV $\mathrm{V}_{\max }$ ) and clinical information (lymph node metastasis and distant metastasis)

KRAS, kirsten rat sarcoma viral oncogene homolog; EGFR, epidermal growth factor receptor; GGN, ground-glass nodule; GGO, ground-glass opacity; SUV, standardized uptake value 
never smoked is the seventh leading cause of cancer-related mortality (46). Several factors contributing to the increased risk of lung cancer in non-smokers included secondhand smoking, occupational exposure, indoor air pollution, and genetic susceptibility. In a study of such non-smoking patients, adenocarcinoma was the mainly pathological type, followed by squamous cell carcinoma, which is the same as previous studies (47).

Nodal involvement and radiotherapy were both risk factors for survival in multiple lung cancer. Lymph node involvement represents metastasis of tumors and affects patient staging and treatment options $(48,49)$. Radiation therapy destroys lung cancer cells by using high-energy beams called X-rays to damage their DNA. However, this treatment may damage patients' lungs, causing a cough, breathing problems, and shortness of breath. The side effects of long-term application of radiotherapy have been clearly demonstrated to reduce patients' quality of life $(50,51)$. In the MPLC patients, smoking history was significantly associated with a poor prognosis. Tobacco smoking is the major cause of all major histological types of lung cancer $(52,53)$. Numerous studies have confirmed that tobacco is a risk factor for lung cancer, with the relative risk for smokers being 1.8 times higher than that for nonsmokers (RR $=1.8,95 \%$ CI: 1.4-2.2) (54). In the IPM patients, the prognosis of patients with two nodules was worse than that of patients with three or more nodules, which is probably due to timely treatment after nodule detection. Otherwise, this may be an inaccurate result caused by the uneven inclusion of patients in each group.

In this large-scale study of 576 patients with multiple lung cancers, we proposed a comprehensive algorithm for differentiating patients with multiple lung tumors and validated the poor survival rate of IPM. However, this study also had some limitations. First, it was a retrospective analysis with inherent selection bias: only operated patients were considered because detailed pathological information could only be observed after surgical removal of the lesion. According to our literature review, the number of eligible patients with multiple lung tumors ranged from 20 to 357. Our sample size is relatively large including 576 patients with 1,295 tumors in the current study. Also, prospective validation is still required to implement this classification on a large scale of multicenter. In the future, it may be possible to achieve the non-invasive judgment of preoperative nodules by using artificial intelligence, and there have been some reports that CT imaging analysis can predict the degree of histologic tissue invasion or subcentimeter pulmonary adenocarcinomas $(55,56)$. Another limitation was that the actual process of metastasis was too complex to be judged based on several indicators. Traditionally, it was believed that there was a physical channel for malignant cell transfer from one site to another; it was for this reason that nodal and systemic metastasis were used as important criteria for IPM in this study. However, this speculative hypothesis has been called into question in recent years. Scientific evidence has demonstrated that the spread of tumors does not depend on physical metastases but on other determinants $(18,19)$. All factors need larger prospective studies from multiple centers to verify their causality and underlying mechanisms.

In conclusion, our results indicated that the comprehensive algorithm was a relevant tool for classifying multifocal lung cancers, which could guide treatment decisions. Patients with IPM clearly differed from patients with MPLC in terms of clinical features and survival status. No nodal involvement and not receiving radiotherapy were associated with superior OS in patients with multiple lung tumors.

\section{Acknowledgments}

Funding: This work was supported by grants 81871890 and 91859203 from National Natural Science Foundation of China, grant 2017-CY02-00030-GX from the Science and Technology Project of Chengdu.

\section{Footnote}

Reporting Checklist: The authors have completed the MDAR reporting checklist. Available at http://dx.doi.org/10.21037/ atm-20-5505

Data Sharing Statement: Available at http://dx.doi. org/10.21037/atm-20-5505

Conflicts of Interest: All authors have completed the ICMJE uniform disclosure form (available at http://dx.doi. org/10.21037/atm-20-5505). The authors have no conflicts of interest to declare.

Ethical Statement: The authors are accountable for all aspects of the work in ensuring that questions related to the accuracy or integrity of any part of the work are appropriately investigated and resolved. The study was conducted in accordance with the Declaration of Helsinki (as revised in 2013), and the ethics committee of West China Hospital has approved this study (Project No. 2019-195). 
Because of the retrospective nature of the research, the requirement for informed consent was waived.

Open Access Statement: This is an Open Access article distributed in accordance with the Creative Commons Attribution-NonCommercial-NoDerivs 4.0 International License (CC BY-NC-ND 4.0), which permits the noncommercial replication and distribution of the article with the strict proviso that no changes or edits are made and the original work is properly cited (including links to both the formal publication through the relevant DOI and the license). See: https://creativecommons.org/licenses/by-nc-nd/4.0/.

\section{References}

1. van der Aalst CM, Ten Haaf K, de Koning HJ. Lung cancer screening: latest developments and unanswered questions. Lancet Respir Med 2016;4:749-61.

2. Aberle DR, Adams AM, Berg CD, et al. Reduced lungcancer mortality with low-dose computed tomographic screening. N Engl J Med 2011;365:395-409.

3. Girard N, Ostrovnaya I, Lau C, et al. Genomic and mutational profiling to assess clonal relationships between multiple non-small cell lung cancers. Clin Cancer Res 2009;15:5184-90.

4. Flieder DB, Vazquez M, Carter D, et al. Pathologic findings of lung tumors diagnosed on baseline CT screening. Am J Surg Pathol 2006;30:606-13.

5. Arai J, Tsuchiya T, Oikawa M, et al. Clinical and molecular analysis of synchronous double lung cancers. Lung Cancer 2012;77:281-7.

6. Vazquez M, Carter D, Brambilla E, et al. Solitary and multiple resected adenocarcinomas after CT screening for lung cancer: histopathologic features and their prognostic implications. Lung Cancer 2009;64:148-54.

7. Tucker MA, Murray N, Shaw EG, et al. Second primary cancers related to smoking and treatment of small-cell lung cancer. Lung Cancer Working Cadre. J Natl Cancer Inst 1997;89:1782-8.

8. Goldstraw P, Crowley J, Chansky K, et al. The IASLC Lung Cancer Staging Project: proposals for the revision of the TNM stage groupings in the forthcoming (seventh) edition of the TNM Classification of malignant tumours. J Thorac Oncol 2007;2:706-14.

9. Detterbeck FC, Marom EM, Arenberg DA, et al. The IASLC Lung Cancer Staging Project: Background Data and Proposals for the Application of TNM Staging Rules to Lung Cancer Presenting as Multiple Nodules with
Ground Glass or Lepidic Features or a Pneumonic Type of Involvement in the Forthcoming Eighth Edition of the TNM Classification. J Thorac Oncol 2016;11:666-80.

10. Detterbeck FC, Franklin WA, Nicholson AG, et al. The IASLC Lung Cancer Staging Project: Background Data and Proposed Criteria to Distinguish Separate Primary Lung Cancers from Metastatic Foci in Patients with Two Lung Tumors in the Forthcoming Eighth Edition of the TNM Classification for Lung Cancer. J Thorac Oncol 2016;11:651-65.

11. Ono K, Sugio K, Uramoto H, et al. Discrimination of multiple primary lung cancers from intrapulmonary metastasis based on the expression of four cancer-related proteins. Cancer 2009;115:3489-500.

12. Jiang L, He J, Shi X, et al. Prognosis of synchronous and metachronous multiple primary lung cancers: systematic review and meta-analysis. Lung Cancer 2015;87:303-10.

13. Martini N, Melamed MR. Multiple primary lung cancers. J Thorac Cardiovasc Surg 1975;70:606-12.

14. Detterbeck FC, Jones DR, Kernstine KH, et al. Lung cancer. Special treatment issues. Chest 2003;123:244S-58S.

15. Shen KR, Meyers BF, Larner JM, et al. Special treatment issues in lung cancer: ACCP evidencebased clinical practice guidelines (2nd edition). Chest 2007;132:290S-305S.

16. Kozower BD, Larner JM, Detterbeck FC, et al. Special treatment issues in non-small cell lung cancer: Diagnosis and management of lung cancer, 3rd ed: American College of Chest Physicians evidence-based clinical practice guidelines. Chest 2013;143:e369S-99S.

17. Girard N, Deshpande C, Lau C, et al. Comprehensive histologic assessment helps to differentiate multiple lung primary nonsmall cell carcinomas from metastases. Am J Surg Pathol 2009;33:1752-64.

18. Valastyan S, Weinberg RA. Tumor metastasis: molecular insights and evolving paradigms. Cell 2011;147:275-92.

19. Wan L, Pantel K, Kang Y. Tumor metastasis: moving new biological insights into the clinic. Nat Med 2013;19:1450-64.

20. Dacic S, Ionescu DN, Finkelstein S, et al. Patterns of allelic loss of synchronous adenocarcinomas of the lung. Am J Surg Pathol 2005;29:897-902.

21. Wang X, Wang M, MacLennan GT, et al. Evidence for common clonal origin of multifocal lung cancers. J Natl Cancer Inst 2009;101:560-70.

22. Murphy SJ, Aubry MC, Harris FR, et al. Identification of independent primary tumors and intrapulmonary metastases using DNA rearrangements in non-small-cell 
lung cancer. J Clin Oncol 2014;32:4050-8.

23. Murphy SJ, Harris FR, Kosari F, et al. Using genomics to differentiate multiple primaries from metastatic lung cancer. J Thorac Oncol 2019;14:1567-82.

24. Warth A, Macher-Goeppinger S, Muley T, et al. Clonality of multifocal nonsmall cell lung cancer: implications for staging and therapy. Eur Respir J 2012;39:1437-42.

25. Schmid K, Oehl N, Wrba F, et al. EGFR/KRAS/ BRAF mutations in primary lung adenocarcinomas and corresponding locoregional lymph node metastases. Clin Cancer Res 2009;15:4554-60.

26. Mansuet-Lupo A, Barritault M, Alifano M, et al. Proposal for a Combined Histomolecular Algorithm to Distinguish Multiple Primary Adenocarcinomas from Intrapulmonary Metastasis in Patients with Multiple Lung Tumors. J Thorac Oncol 2019;14:844-56.

27. Patel SB, Kadi W, Walts AE, et al. Next-Generation Sequencing: A Novel Approach to Distinguish Multifocal Primary Lung Adenocarcinomas from Intrapulmonary Metastases. J Mol Diagn 2017;19:870-80.

28. Roepman P, Ten Heuvel A, Scheidel KC, et al. Added Value of 50-Gene Panel Sequencing to Distinguish Multiple Primary Lung Cancers from Pulmonary Metastases: A Systematic Investigation. J Mol Diagn 2018;20:436-45.

29. Chang JC, Alex D, Bott M, et al. Comprehensive NextGeneration Sequencing Unambiguously Distinguishes Separate Primary Lung Carcinomas From Intrapulmonary Metastases: Comparison with Standard Histopathologic Approach. Clin Cancer Res 2019;25:7113-25.

30. Suh YJ, Lee HJ, Sung P, et al. A Novel Algorithm to Differentiate Between Multiple Primary Lung Cancers and Intrapulmonary Metastasis in Multiple Lung Cancers With Multiple Pulmonary Sites of Involvement. J Thorac Oncol 2020;15:203-15.

31. Travis WD, Brambilla E, Nicholson AG, et al. The 2015 World Health Organization Classification of Lung Tumors: Impact of Genetic, Clinical and Radiologic Advances Since the 2004 Classification. J Thorac Oncol 2015;10:1243-60.

32. Park EA, Lee HJ, Kim YT, et al. EGFR gene copy number in adenocarcinoma of the lung by FISH analysis: investigation of significantly related factors on CT, FDGPET, and histopathology. Lung Cancer 2009;64:179-86.

33. Cohen, Educational JJ, Measurement P. A Coefficient of Agreement for Nominal Scales. 1960;20:37-46.

34. Carey FA, Donnelly SC, Walker WS, et al. Synchronous primary lung cancers: prevalence in surgical material and clinical implications. Thorax 1993;48:344-6.

35. Henschke CI, McCauley DI, Yankelevitz DF, et al. Early Lung Cancer Action Project: overall design and findings from baseline screening. Lancet 1999;354:99-105.

36. Goldstraw P, Chansky K, Crowley J, et al. The IASLC Lung Cancer Staging Project: Proposals for Revision of the TNM Stage Groupings in the Forthcoming (Eighth) Edition of the TNM Classification for Lung Cancer. J Thorac Oncol 2016;11:39-51.

37. Yu YC, Hsu PK, Yeh YC, et al. Surgical results of synchronous multiple primary lung cancers: similar to the stage-matched solitary primary lung cancers? Ann Thorac Surg 2013;96:1966-74.

38. Cheng H, Lei BF, Peng PJ, et al. Histologic lung cancer subtype differentiates synchronous multiple primary lung adenocarcinomas from intrapulmonary metastases. J Surg Res 2017;211:215-22.

39. Fonseca A, Detterbeck FC. How many names for a rose: inconsistent classification of multiple foci of lung cancer due to ambiguous rules. Lung Cancer 2014;85:7-11.

40. Homer RJ. Pathologists' staging of multiple foci of lung cancer: poor concordance in absence of dramatic histologic or molecular differences. Am J Clin Pathol 2015;143:701-6.

41. Rare lung cancers. Breathe (Sheff) 2015;11:323-30.

42. Bethune G, Bethune D, Ridgway N, et al. Epidermal growth factor receptor (EGFR) in lung cancer: an overview and update. J Thorac Dis 2010;2:48-51.

43. Gibbons DL, Byers LA, Kurie JM. Smoking, p53 mutation, and lung cancer. Mol Cancer Res 2014;12:3-13.

44. Mitsudomi T, Yatabe Y, Koshikawa T, et al. Mutations of the P53 tumor suppressor gene as clonal marker for multiple primary lung cancers. J Thorac Cardiovasc Surg 1997;114:354-60.

45. Ettinger DS, Wood DE, Aggarwal C, et al. NCCN Guidelines Insights: Non-Small Cell Lung Cancer, Version 1.2020. J Natl Compr Canc Netw 2019;17:1464-72.

46. Rivera GA, Wakelee H. Lung Cancer in Never Smokers. Adv Exp Med Biol 2016;893:43-57.

47. Guo H, Mao F, Zhang H, et al. Analysis on the Prognostic and Survival Factors of Synchronous Multiple Primary Lung Cancer. Zhongguo Fei Ai Za Zhi 2017;20:21-7.

48. Rusch VW, Asamura H, Watanabe H, et al. The IASLC lung cancer staging project: a proposal for a new international lymph node map in the forthcoming seventh edition of the TNM classification for lung cancer. J Thorac Oncol 2009;4:568-77. 
49. Keller SM, Vangel MG, Wagner H, et al. Prolonged survival in patients with resected non-small cell lung cancer and single-level N2 disease. J Thorac Cardiovasc Surg 2004;128:130-7.

50. Baker S, Dahele M, Lagerwaard FJ, et al. A critical review of recent developments in radiotherapy for non-small cell lung cancer. Radiat Oncol 2016;11:115.

51. Yang H, Jin T, Li M, et al. Synergistic effect of immunotherapy and radiotherapy in non-small cell lung cancer: current clinical trials and prospective challenges. Precision Clinical Medicine 2019;2:57-70.

52. Malhotra J, Malvezzi M, Negri E, et al. Risk factors for lung cancer worldwide. Eur Respir J 2016;48:889-902.

53. Leduc C, Antoni D, Charloux A, et al. Comorbidities in the management of patients with lung cancer. Eur Respir J

Cite this article as: Shao J, Wang C, Li J, Song L, Li L, Tian $\mathrm{P}, \mathrm{Li} \mathrm{W}$. A comprehensive algorithm to distinguish between MPLC and IPM in multiple lung tumors patients. Ann Transl Med 2020;8(18):1137. doi: 10.21037/atm-20-5505
2017;49:1601721.

54. Liang HY, Li XL, Yu XS, et al. Facts and fiction of the relationship between preexisting tuberculosis and lung cancer risk: a systematic review. Int J Cancer 2009;125:2936-44.

55. Varghese C, Rajagopalan S, Karwoski RA, et al. Computed Tomography-Based Score Indicative of Lung Cancer Aggression (SILA) Predicts the Degree of Histologic Tissue Invasion and Patient Survival in Lung Adenocarcinoma Spectrum. J Thorac Oncol 2019;14:1419-29.

56. Zhao W, Yang J, Sun Y, et al. 3D Deep Learning from CT Scans Predicts Tumor Invasiveness of Subcentimeter Pulmonary Adenocarcinomas. Cancer Res 2018;78:6881-9. 


\section{Supplementary}

Table S1 Commonly cited criteria to distinguish separate primary lung cancer from metastasis

\begin{tabular}{|c|c|}
\hline Martini and Melamed criteria & $X X X$ \\
\hline Similar histologic type & IPM \\
\hline \multicolumn{2}{|l|}{ Same segment } \\
\hline \multicolumn{2}{|l|}{ Different segment } \\
\hline No carcinoma in situ, or carcinoma in lymphatics common to both, or systemic metastasis & IPM \\
\hline Different histologic type & MPLC \\
\hline \multicolumn{2}{|l|}{ Metachronous tumors } \\
\hline Foci of carcinoma in situ & MPLC \\
\hline \multicolumn{2}{|l|}{ Time interval $<2$ y } \\
\hline \multicolumn{2}{|l|}{ Similar histologic type } \\
\hline Same lobe & IPM \\
\hline \multicolumn{2}{|l|}{ Different lobe } \\
\hline No carcinoma in lymphatics common to both, and no systemic metastasis & MPLC \\
\hline Carcinoma in lymphatics common to both, or systemic metastasis & IPM \\
\hline Different histologic type & MPLC \\
\hline \multicolumn{2}{|l|}{ ACCP criteria } \\
\hline Same histology, anatomically separated & MPLC \\
\hline \multicolumn{2}{|l|}{$\geq 4$-year interval between cancers } \\
\hline \multicolumn{2}{|l|}{ No systemic metastases from either cancer } \\
\hline \multicolumn{2}{|l|}{ Different histology } \\
\hline \multicolumn{2}{|l|}{ Different histologic type } \\
\hline \multicolumn{2}{|l|}{ Different molecular genetic characteristics } \\
\hline \multicolumn{2}{|l|}{ Arising separately from foci of carcinoma in situ } \\
\hline Same histology and multiple systemic metastases & IPM \\
\hline \multicolumn{2}{|l|}{ Same histology, in different lobes } \\
\hline \multicolumn{2}{|l|}{ And presence of $\mathrm{N} 2,3$ involvement } \\
\hline Or <2-year interval & \\
\hline
\end{tabular}


Table S2 Univariate and multivariate analyses of overall survival in 405 patients with MPLC

\begin{tabular}{|c|c|c|c|c|c|}
\hline \multirow{2}{*}{ Variable } & \multicolumn{3}{|c|}{ Univariate analysis } & \multicolumn{2}{|c|}{ Multivariate analyses } \\
\hline & Overall survival $(95 \% \mathrm{Cl})$ & $P$ value & $\mathrm{HR}(95 \% \mathrm{Cl})$ & $P$ value & $\mathrm{HR}(95 \% \mathrm{Cl})$ \\
\hline Gender & & $<0.001$ & $0.31(0.17-0.57)$ & 0.376 & \\
\hline Male & $42 \%(22-86 \%)$ & & & & \\
\hline Female & $81 \%(66-211 \%)$ & & & & \\
\hline Age & & 0.09 & $1.56(0.94-2.61)$ & & \\
\hline$\leq 60$ years & $64 \%(42-146 \%)$ & & & & \\
\hline$>60$ years & $46 \%(24-93 \%)$ & & & & \\
\hline Smoking history & & $<0.001$ & $5.37(2.95-9.78)$ & 0.004 & $8.61(1.95-37.94)$ \\
\hline No & $80 \%(65-206 \%)$ & & & & \\
\hline Yes & $30 \%(8-46 \%)$ & & & & \\
\hline Number of lesions & & 0.02 & $0.3(0.11-0.82)$ & 0.79 & \\
\hline 2 & $48 \%(29-105 \%)$ & & & & \\
\hline$\geq 3$ & $89 \%(77-240 \%)$ & & & & \\
\hline Tumor chronology & & 0.35 & $0.77(0.45-1.33)$ & & \\
\hline Synchronous & $72 \%(59-186 \%)$ & & & & \\
\hline Metachronous & $56 \%(39-133 \%)$ & & & & \\
\hline Location & & 0.75 & $0.86(0.34-2.16)$ & & \\
\hline Same lobe & $45 \%(-17-11 \%)$ & & & & \\
\hline Different lobes & $56 \%(40-135 \%)$ & & & & \\
\hline Nodal involvement & & $<0.001$ & $3.99(2.17-7.33)$ & 0.47 & \\
\hline NO or Nx (both tumors) & $64 \%(49-161 \%)$ & & & & \\
\hline N-positive ( $\geq 1$ tumor) & $26 \%(-1-23 \%)$ & & & & \\
\hline Pleural invasion & & 0.007 & $2.06(1.22-3.49)$ & 0.51 & \\
\hline No (both tumors) & $59 \%(34-125 \%)$ & & & & \\
\hline Yes ( $\geq 1$ tumor) & $58 \%(44-144 \%)$ & & & & \\
\hline Chemotherapy & & 0.33 & $1.29(0.77-2.17)$ & & \\
\hline No & $75 \%(65-202 \%)$ & & & & \\
\hline Yes & $45 \%(23-89 \%)$ & & & & \\
\hline Radiotherapy & & 0.003 & $2.63(1.4-4.94)$ & 0.6 & \\
\hline No & $65 \%(47-157 \%)$ & & & & \\
\hline Yes & $29 \%(5-40 \%)$ & & & & \\
\hline EGFR status & & $<0.001$ & $0.25(0.12-0.54)$ & 0.06 & \\
\hline Wild-type & $27 \%(-12-4 \%)$ & & & & \\
\hline Mutated & $73 \%(51-172 \%)$ & & & & \\
\hline PD-L1 & & 0.001 & $10.69(2.53-45.09)$ & 0.15 & \\
\hline Negative & $66 \%(13-92 \%)$ & & & & \\
\hline Positive & $18 \%(-9-1 \%)$ & & & & \\
\hline
\end{tabular}

MPLC, multiple primary lung cancer; EGFR, epidermal growth factor receptor; PD-L1, programmed death-ligand 1. 
Table S3 Univariate and multivariate analyses of overall survival in 171 patients with IPM

\begin{tabular}{|c|c|c|c|}
\hline \multirow{2}{*}{ Variable } & \multicolumn{3}{|c|}{ Univariate analysis } \\
\hline & Overall survival $(95 \% \mathrm{Cl})$ & $P$ value & $\mathrm{HR}(95 \% \mathrm{Cl})$ \\
\hline Gender & & 0.50 & $0.86(0.55-1.35)$ \\
\hline Male & $18 \%(5-31 \%)$ & & \\
\hline Female & $25 \%(8-43 \%)$ & & \\
\hline Age & & 0.61 & $1.12(0.73-1.73)$ \\
\hline$\leq 60$ years & $20 \%(6-33 \%)$ & & \\
\hline$>60$ years & $20 \%(4-37 \%)$ & & \\
\hline Smoking history & & 0.51 & $1.16(0.75-1.78)$ \\
\hline No & $18 \%(3-33 \%)$ & & \\
\hline Yes & $23 \%(8-39 \%)$ & & \\
\hline Number of lesions & & 0.05 & $0.51(0.26-1.00)$ \\
\hline 2 & $11 \%(1-21 \%)$ & & \\
\hline$\geq 3$ & $55 \%(32-77 \%)$ & & \\
\hline Tumor chronology & & 0.31 & $0.8(0.51-1.24)$ \\
\hline Synchronous & $12 \%(-8-31 \%)$ & & \\
\hline Metachronous & $22 \%(9-35 \%)$ & & \\
\hline Location & & 0.07 & $0.5(0.24-1.06)$ \\
\hline Same lobe & $39 \%(12-67 \%)$ & & \\
\hline Different lobes & $21 \%(10-32 \%)$ & & \\
\hline Nodal involvement & & 0.47 & $1.27(0.66-2.48)$ \\
\hline NO or Nx (both tumors) & $23 \%(-3-49 \%)$ & & \\
\hline N-positive ( $\geq 1$ tumor) & $19 \%(7-31 \%)$ & & \\
\hline Pleural invasion & & 0.97 & $0.99(0.63-1.55)$ \\
\hline No (both tumors) & $26 \%(7-45 \%)$ & & \\
\hline Yes ( $\geq 1$ tumor) & $14 \%(1-26 \%)$ & & \\
\hline Chemotherapy & & 0.63 & $0.89(0.56-1.42)$ \\
\hline No & $29 \%(12-47 \%)$ & & \\
\hline Yes & $15 \%(2-28 \%)$ & & \\
\hline Radiotherapy & & 0.25 & $1.35(0.81-2.23)$ \\
\hline No & $22 \%(8-36 \%)$ & & \\
\hline Yes & $10 \%(-3-23 \%)$ & & \\
\hline EGFR status & & 0.55 & $0.84(0.48-1.48)$ \\
\hline Wild-type & $20 \%(0.5-39 \%)$ & & \\
\hline Mutated & $24 \%(0.2-47 \%)$ & & \\
\hline PD-L1 & & 0.34 & $1.68(0.58-4.92)$ \\
\hline Negative & 0 & & \\
\hline Positive & $12 \%(-1-25 \%)$ & & \\
\hline
\end{tabular}

IPM, intrapulmonary metastasis; EGFR, epidermal growth factor receptor; PD-L1, programmed death-ligand 1. 
Table S4 Overall survival of patients with multiple lung cancers in previous studies

\begin{tabular}{|c|c|c|c|c|c|c|c|}
\hline First author & Year & \multicolumn{2}{|c|}{ No. of patients } & Definition & \multicolumn{2}{|c|}{ 5-year overall survival } & $\mathrm{HR}(95 \% \mathrm{Cl})$ \\
\hline Kenji Ono & 2009 & 25 & 45 & Protein expression profile & $40.2 \%$ & $81.1 \%$ & $4.03(1.71-9.50)$ \\
\hline Junuchi Aria & 2012 & 80 & 39 & Genomic alteration profile & $47.4 \%$ & $54.8 \%$ & $1.38(0.80-2.38)$ \\
\hline Yu-Chao Yu & 2013 & 77 & 97 & Martini and Melamed criteria & $23.7 \%$ & $69.6 \%$ & $3.70(2.23-6.14)$ \\
\hline Audrey Mansuet-Lupo & 2019 & 33 & 78 & Histological and molecular profile & $50 \%$ & $62 \%$ & $1.3(0.7-2.2)$ \\
\hline
\end{tabular}

IPM, intrapulmonary metastasis; MPLC, multiple primary lung cancer. 